\title{
SISTEMA DE LAGOAS DE ESTABILIZAÇÃO NO TRATAMENTO DE ÁGUAS RESIDUÁRIAS
}

\author{
Jamille dos Reis Amorim - jamillereisamorim@ gmail.com \\ Universidade Católica Dom Bosco \\ Eduarda Maria Farias Silva - eduardafariass@ hotmail.com \\ Instituto Federal do Ceará \\ Priscila Sabioni Cavalheri - priscilasabioni@ hotmail.com \\ Universidade Católica Dom Bosco
}

Resumo

O trabalho foi realizado na base de pesquisa Instituto São Vicente - Lagoa da Cruz, no município de Campo Grande - MS. Teve como objetivo avaliação da eficiência de uma estação de tratamento de esgoto constituída por um sistema de tratamento preliminar, seguido de um decantador primário (tanque séptico), duas lagoas facultativas e uma de maturação em série, e tratamento terciário por meio de desinfecção, tendo como última operação o escoamento superficial no solo. $\mathrm{O}$ monitoramento foi realizado no esgoto bruto, na caixa de passagem e no efluente da lagoa de maturação, durante um período de quatro meses (setembro a dezembro de 2016), foi analisado os parâmetros pH, temperatura, turbidez, oxigênio dissolvido, demanda bioquímica de oxigênio, sólidos suspensos, sólidos sedimentáveis, nitrogênio total, coliformes termotolerantes e totais. Foi verificado que houve uma eficiência em todos os parâmetros acima analisados.

Introdução

Nos últimos anos a preocupação com as questões ambientais vem sendo bastante discutida, uma vez que o desequilíbrio gerado de uma forma global encaminha-se ao 


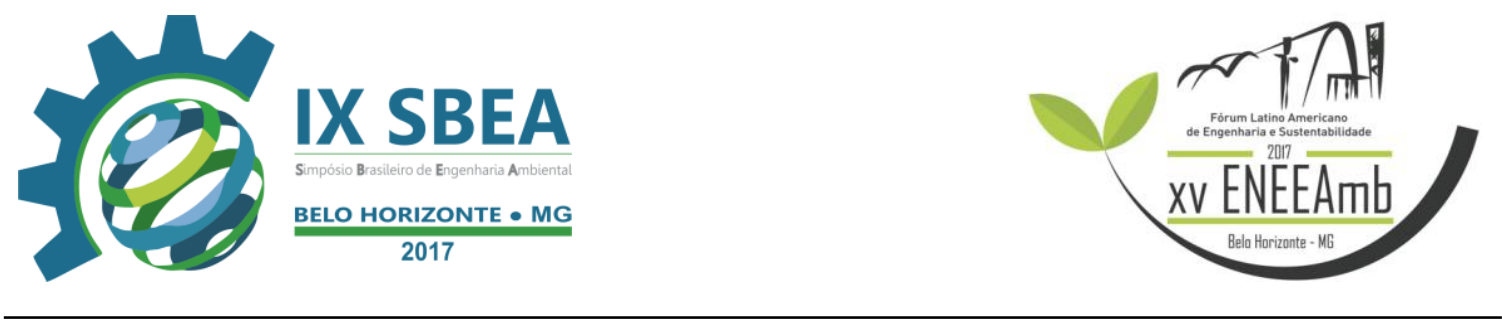

surgimento de grandes impactos ambientais negativos na sociedade. Umas dessas problemáticas são resultantes do descarte indevido de esgoto doméstico no meio ambiente (PALMEIRA, 2014). Águas residuárias são compostas de 99,9\% de água, sendo $0,1 \%$ restantes compreendem sólidos orgânicos e inorgânicos dissolvidos e suspensos, bem como microrganismos (VON SPERLING, 2002). A contaminação das águas pelos esgotos gera implicações ambientais e implicações na saúde pública, pois, a saúde de uma população está interligada a qualidade da água consumida. A contaminação por substâncias orgânicas e degradáveis entre elas, o nitrogênio, o fósforo, acarretam uma grande proliferação de organismos autótrofos que passam a consumir grande parte do oxigênio dissolvido na água, causando a morte da fauna local (BONACELLA, 2007)

Esse trabalho realizou um estudo da eficiência da ETE Lagoa da Cruz para verificar se os parâmetros estão dentro dos padrões aceitáveis pela legislação (Conselho Estadual de Controle Ambienta - CECA e Conselho Nacional do Meio Ambiente CONAMA), para contribuir para a melhoria da qualidade da água do Córrego Segredo, minimizando os impactos ambientas.

\section{Metodologia}

A estação de tratamento de esgotos na base de pesquisa Instituto São Vicente Lagoa da Cruz está localizada na cidade de Campo Grande, no estado de Mato Grosso do Sul, centro-oeste do Brasil, região tropical de coordenadas: 20²6’34" latitude Sul e 54³8'47” longitude Oeste, 532 metros de altitude. A região para implantação da pesquisa, segundo KOPPEN \& GEIGER (1928) se encontra na faixa entre o mesotérmico úmido sem estiagem apresentando temperaturas superiores a $22^{\circ} \mathrm{C}$ no mês seco e o clima tropical úmido com estação chuvosa no verão e seca no inverno, com temperaturas médias entre $19^{\circ} \mathrm{C}$ e $25^{\circ} \mathrm{C}$.

Área de Estudo e Coleta

A área de estudo refere-se à bacia do Segredo localizada na cidade de Campo Grande -MS, que por sua vez faz parte da Bacia Hidrográfica do Rio Paraná.Com uma 


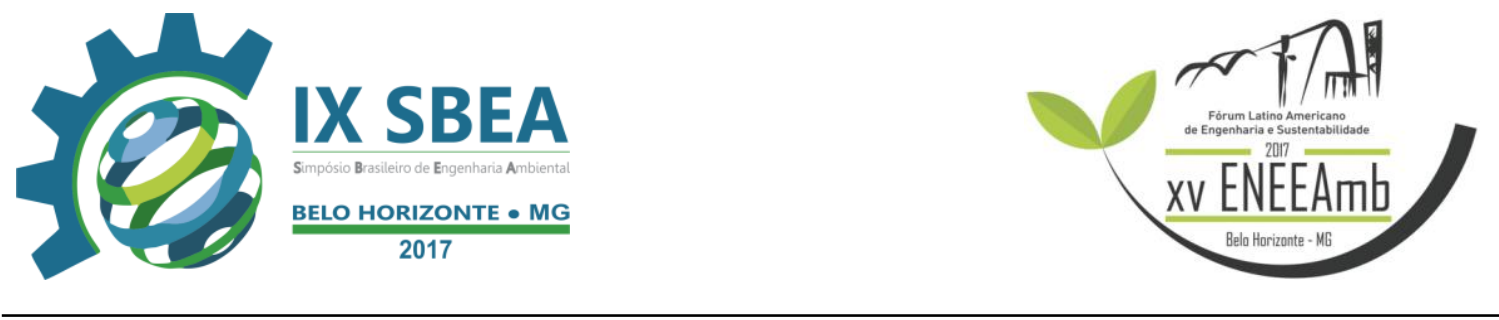

área de 8.096,05 $\mathrm{Km}^{2}$, Campo Grande possui mais de dezesseis córregos que banham a cidade, sendo que a maioria deságua no principal corpo receptor, o Anhanduizinho (IBGE,2012). Os córregos urbanos de Campo Grande - MS podem estar recebendo uma carga de poluentes onde uma série de compostos pode estar sendo diluídos por dispersão, difusão e transformações químicas e microbiológicas.A carta de drenagem de Campo Grande/MS (1997), feita pelo Instituto Municipal de Planejamento Urbano e de Meio Ambiente, é constituída por dez microbacais, porém a área estudada é localizada na microbacia do segredo, com área de $46.1 \mathrm{~km}^{2}$. O córrego Segredo deságua nas águas do córrego Anhanduizinho, porém sua nascente encontra-se na lagoa da fazenda escola - Instituto São Vicente.

As etapas de coletas foram executadas nos dias 23/Setembro, 08/Novembro e 05/Dezembro, no ponto P1 - esgoto bruto, ponto P2 - caixa de passagem e no ponto P3 - efluente da lagoa de maturação (terceira lagoa),conforme mostrado na figura 1.
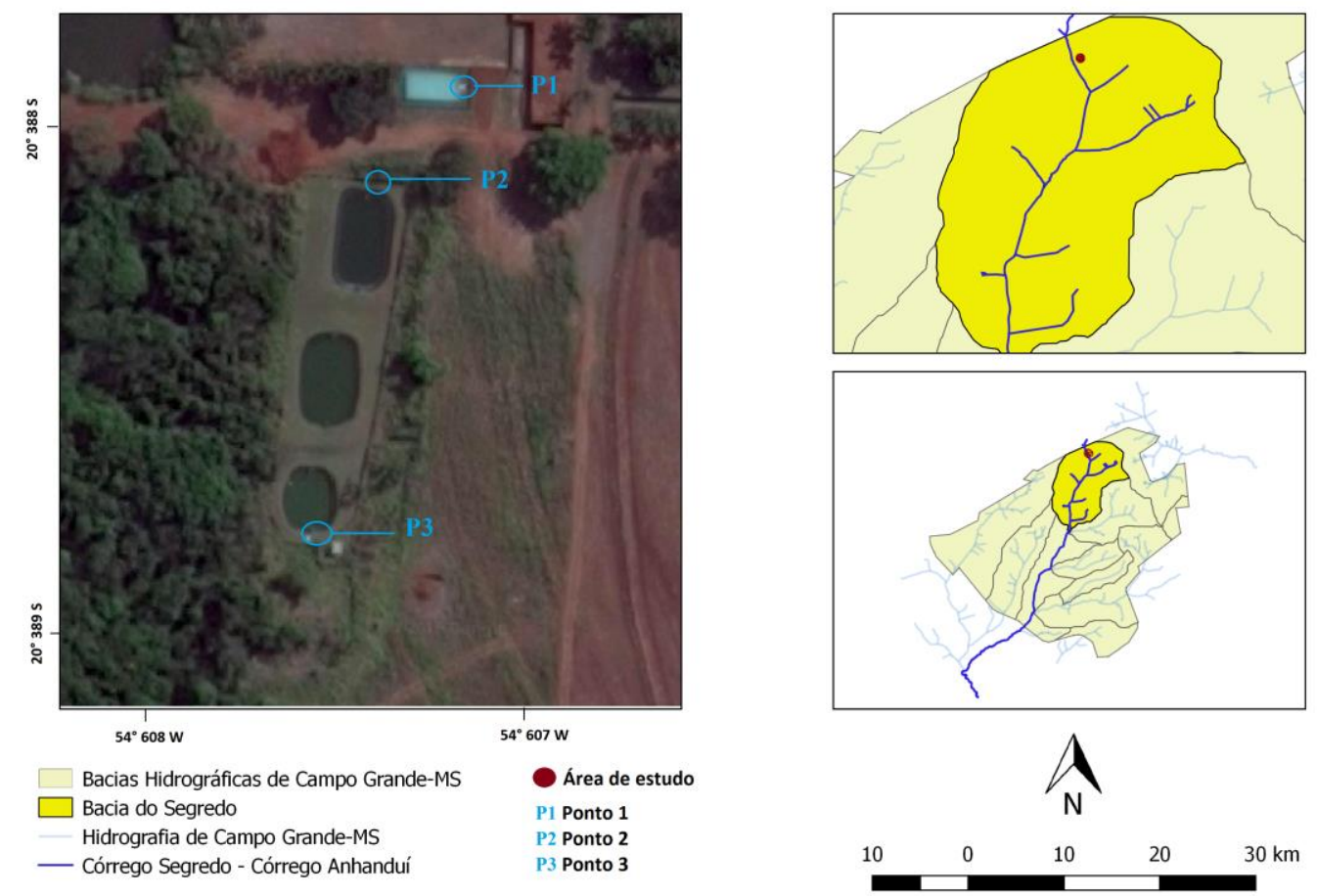

Figura 1 - delimitação das bacias hidrográfica de Campo Grande - MS, bacia do Segredo, Córrego Segredo/Anhanduí, Área de estudo e pontos de coleta, P1, P2 e P3. 
Localização

A tabela 1 mostra os pontos de interesse do estudo, todos os pontos têm coordenadas em UTM (Universal Transversa de Mercator) e Datum WGS 84 conforme tabela 1:

Tabela 1 - Coordenadas dos pontos em UTM e Datum WGS 84

\begin{tabular}{|l|l|l|}
\hline Pontos & Longitude UTM & Latitude UTM \\
\hline P1 & $749660.16 \mathrm{E}$ & $7743718.40 \mathrm{~S}$ \\
\hline P2 & $749635.41 \mathrm{E}$ & $7743694.48 \mathrm{~S}$ \\
\hline P3 & $749620.48 \mathrm{E}$ & $7743614.11 \mathrm{~S}$ \\
\hline
\end{tabular}

Uso e Ocupação Do Solo

No município de Campo Grande as unidades de mapeamento com domínio de solos da classe dos Latossolos Vermelhos ocorrem em cerca de 335.000 ha, que representam quase $45 \%$ da área total do município (Embrapa, 2008). O escoamento superficial ocorre por trincheiras, ou seja, o esgoto efluente escoa através de curvas de nível, ocorrendo à infiltração no solo.

Resultados e Discussões

A tabela 2 representa os resultados obtidos nas três campanhas do ponto P1 esgoto bruto, a tabela 3 demonstra os resultados do ponto P2 - caixa de passagem e na tabela 4 representa os resultados obtidos no ponto P3 - efluente na lagoa de maturação (terceira lagoa). As três campanhas foram realizadas nos dias 24/setembro, 08/novembro e 05/dezembro. 
Tabela 2 - Resultados médios encontrados nas análises realizadas no ponto P1 nas três campanhas e os valores de referência do CONAMA n ${ }^{\circ} 430$, CONAMA $n^{\circ} 357$ e CECA/MS n ${ }^{\circ} 003$.

\begin{tabular}{|c|c|c|c|c|c|c|}
\hline \multirow{2}{*}{ Parâmetros } & \multicolumn{3}{|c|}{ PONTO Pl } & \multicolumn{2}{|c|}{ CONAMA } & \multirow{2}{*}{$\begin{array}{c}\text { CECA/MS } \\
n^{\circ} 003\end{array}$} \\
\hline & $1^{\circ}$ Campanha & $2^{\circ}$ Campanha & $3^{\circ}$ Campanha & $n^{\circ} \mathbf{4 3 0}$ & $n^{\circ} \mathbf{3 5 7}$ & \\
\hline $\mathrm{pH}$ & 6,95 & 6,96 & 7,19 & $5,0-9,0$ & & 6,0 a 10,0 \\
\hline Temperatura $\left({ }^{\circ} \mathrm{C}\right)$ & 23 & 21 & 23 & inferior a $40^{\circ} \mathrm{C}$ & & inferior a $40^{\circ} \mathrm{C}$ \\
\hline Turbidez (UNT) & 95,2 & 18 & 21,33 & & 100 UNT & \\
\hline DQO (mg.02.L-1) & 265,45 & 170,53 & 59,77 & & & \\
\hline Fósforo total (mg.P.L-1) & 20,27 & 3,267 & 1,39 & & & \\
\hline OD (mg.O2.L-1) & 2,8 & 2,43 & 1,7 & & & $\begin{array}{c}\text { não inferior a } 5 \\
\mathrm{mg} \cdot \mathrm{L}^{-1}\end{array}$ \\
\hline DBO (mg.02.L-1) & 92,91 & 30,72 & 25,22 & \begin{tabular}{|c|}
$120,0 \mathrm{mg} \cdot \mathrm{L}^{-1}$ - remoção \\
minima de $60 \%$
\end{tabular} & máximo de $60 \mathrm{mg} . \mathrm{L}^{-1}$ & $\begin{array}{c}\text { máximo de } 60 \\
\mathrm{mg} \cdot \mathrm{L}^{-1}\end{array}$ \\
\hline Sólidos Sedimentáveis (mL.L-l) & 0,5 & 0,5 & 0,5 & $1,0 \mathrm{~mL} \cdot \mathrm{L}^{-1}$ & & Até $1,0 \mathrm{~mL} \cdot \mathrm{L}^{-1}$ \\
\hline Sólidos totais (mg.L-l) & 440 & 320 & 200 & $20 \%$ de eficiencia minima & & \\
\hline Nitrogênio Total (mg.N.L-l) & 12 & 1,817 & 5,25 & & & \\
\hline \begin{tabular}{|l|} 
Coliformes Totais \\
NMIP.(100mL)-1 \\
\end{tabular} & $1,6 \mathrm{E}+09$ & $1,6 \mathrm{E}+09$ & $1,60 \mathrm{E}+09$ & & & \\
\hline $\begin{array}{l}\text { Coliformes Termotolerantes } \\
\text { NMP. }(100 \mathrm{~mL})-1\end{array}$ & $1,6 \mathrm{E}+09$ & $1,6 \mathrm{E}+09$ & $1,30 \mathrm{E}+10$ & & & $\begin{array}{c}1.000 \\
\mathrm{NMP} / 100 \mathrm{ml}\end{array}$ \\
\hline Legenda: & & & & & & \\
\hline
\end{tabular}

Na primeira campanha não teve contribuição de águas pluviais, ocasionando maior consumo de matéria orgânica, já na segunda e terceira campanha sofreu uma alteração, ocasionando a redução da turbidez, DQO, fósforo, DBO, sólidos totais, nitrogênio.

O foco do monitoramento foi quanto à prevenção da poluição de corpos hídricos uma vez que a baixa eficiência no tratamento de águas residuárias com despejo em corpos hídricos podem ocasionar a eutrofização propiciando a mortalidade da vida aquática. 
Tabela 3 - Resultados médios encontrados nas análises realizadas no ponto P2 nas três campanhas e os valores de referência do CONAMA n ${ }^{\circ} 430$, CONAMA $n^{\circ} 357$ e CECA/MS n ${ }^{\circ} 003$.

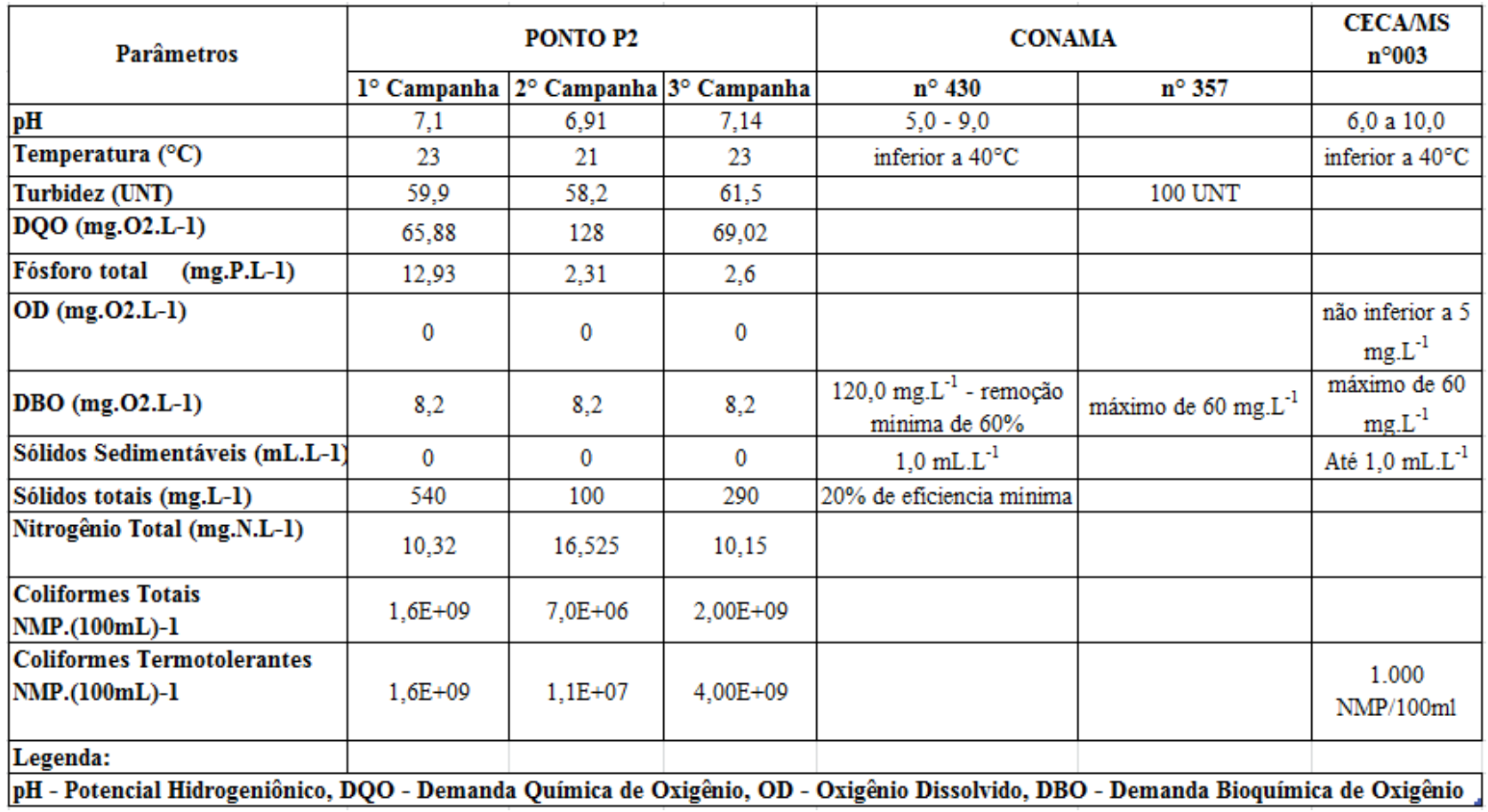

Quanto ao OD, nas três campanhas é zero isto se dá pelo surgimento do elevado número de algas que utilizam a amônia $\left(\mathrm{NH}_{3}\right)$ e outros compostos inorgânicos. Essas algas, na presença de luz solar, fazem a síntese celular liberando oxigênio para o meio líquido. Este processo ocorre somente na parte aeróbica das lagoas facultativas. Isso também modifica o $\mathrm{pH}$ e indiretamente contribui para a volatilização da amônia e proporcionando maior grau de depuração das águas residuárias durante o seu percurso nas lagoas. Os sólidos sedimentáveis, por sua vez, sofreu uma alteração por conta da pequena quantidade de chuva. 
Tabela 4 - Resultados médios encontrados nas análises realizadas no ponto P3 nas três campanhas e os valores de referência do CONAMA n ${ }^{\circ} 430$, CONAMA $n^{\circ} 357$ e CECA/MS n ${ }^{\circ} 003$.

\begin{tabular}{|c|c|c|c|c|c|c|}
\hline \multirow{2}{*}{ Parâmetros } & \multicolumn{3}{|c|}{ PONTO P3 } & \multicolumn{2}{|c|}{ CONAMA } & \multirow{2}{*}{$\begin{array}{l}\text { CECA/MS } \\
n^{\circ} 003\end{array}$} \\
\hline & $1^{\circ} \mathrm{Campanha}$ & $2^{\circ}$ Campanha & $3^{\circ}$ Campanha & $n^{\circ} 430$ & $n^{\circ} 357$ & \\
\hline $\mathrm{pH}$ & 9,64 & 8,66 & 9,09 & $5,0-9,0$ & & 6,0 a 10,0 \\
\hline Temperatura $\left({ }^{\circ} \mathrm{C}\right)$ & 23 & 21 & 23 & inferior a $40^{\circ} \mathrm{C}$ & & inferior a $40^{\circ} \mathrm{C}$ \\
\hline Turbidez (UNT) & 63,6 & 47 & 33,87 & & $100 \mathrm{UNT}$ & \\
\hline DQO (mg.02.L-1) & 46,93 & 58,67 & 47,14 & & & \\
\hline Fósforo total (mg.P.L-l) & 1,4 & 3,926 & 1,2 & & & \\
\hline OD (mg.02.L-1) & 8,4 & 6,73 & 4,5 & & & $\begin{array}{c}\text { não inferior a } 5 \\
\mathrm{mg} \cdot \mathrm{L}^{-1}\end{array}$ \\
\hline DBO (mg.O2.L-1) & 54,77 & 18,1 & 23,69 & $\begin{array}{c}120,0 \text { mg. } \mathrm{L}^{-1} \text { - remoção } \\
\text { minima de } 60 \%\end{array}$ & máximo de $60 \mathrm{mg} \cdot \mathrm{L}^{-1}$ & $\begin{array}{c}\text { máximo de } 60 \\
\mathrm{mg} \cdot \mathrm{L}^{-1}\end{array}$ \\
\hline Sólidos Sedimentáveis (mL.L-l) & 0,1 & 0,5 & 0,5 & $1,0 \mathrm{~mL} \cdot \mathrm{L}^{-1}$ & & Até $1,0 \mathrm{~mL} \cdot \mathrm{L}^{-1}$ \\
\hline Sólidos totais (mg.L-l) & 320 & 200 & 158 & $20 \%$ de eficiencia minima & & \\
\hline Nitrogênio Total (mg.N.L-1) & 2,74 & 1,4 & 2,15 & & & \\
\hline $\begin{array}{l}\text { Coliformes Totais } \\
\text { NMP.(100mL)-1 }\end{array}$ & $9,0 \mathrm{E}+06$ & $2,0 \mathrm{E}+05$ & $9,00 \mathrm{E}+06$ & & & \\
\hline $\begin{array}{l}\text { Coliformes Termotolerantes } \\
\text { NMP.(100mL)-1 }\end{array}$ & $9,0 \mathrm{E}+06$ & $2,0 \mathrm{E}+06$ & $2,00 \mathrm{E}+09$ & & & $\begin{array}{c}1.000 \\
\mathrm{NMP} / 100 \mathrm{ml}\end{array}$ \\
\hline Legenda: & & & & & & \\
\hline
\end{tabular}

De acordo com Resolução CONAMA n 430, o pH só pode ser lançado em corpos hídricos com pH entre 5,0 a 9,0. Sabe-se que nesse tipo de sistema há presença de algas que utilizam de nutrientes e produzem oxigênio no processo de fotossíntese, condição esta que leva o aumento do $\mathrm{pH}$ e reduz no decorrer do tratamento as concentrações de fosfato e nitrogênio.

O oxigênio dissolvido já citado anteriormente, é elevado devido a presença de algas (na lagoa de maturação - próprio ponto p3 que realizam a fotossíntese gerando assim oxigênio.

De acordo com CAERN (2014), a precipitação da água da chuva diretamente sobre o espelho de água da lagoa praticamente não provoca nenhum efeito advero, mas a admissão de águas pluviais nas redes coletoras provoca uma série de problemas tais como a diluição de águas residuárias, diminuição de tempo de retenção, mudança na temperatura da massa líquida e uma redução e até anulação temporária do rendimento 


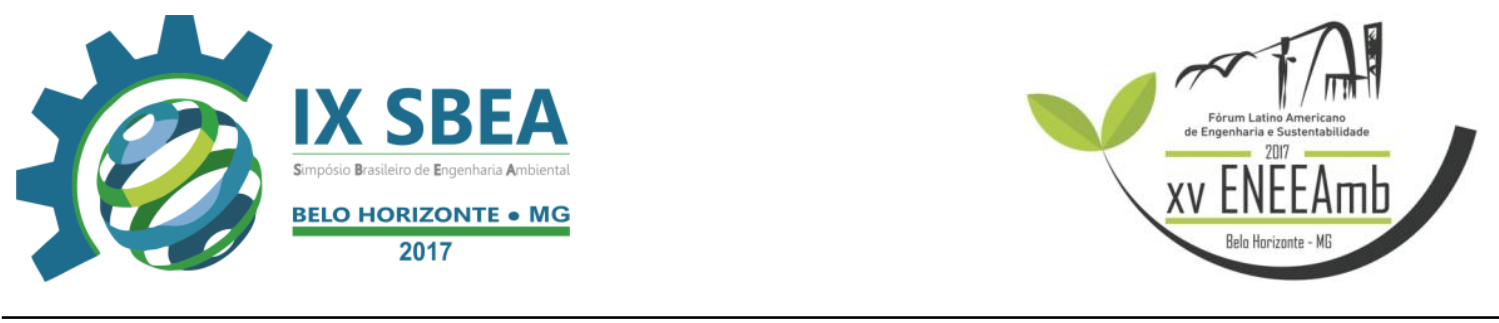

da lagoa. Como pode ser observado no gráfico 1 , a primeira campanha realizada no da 24/Setembro, não foi influenciada pela chuva, já na segunda e teceira campanha realizada nos dias 08/Novembro e 05/Dezembro teve uma pequena interferência, no qual teve a alteração de alguns parâmetros como, turbidez, DQO, fósforo, sólidos totais e nitrogênio.

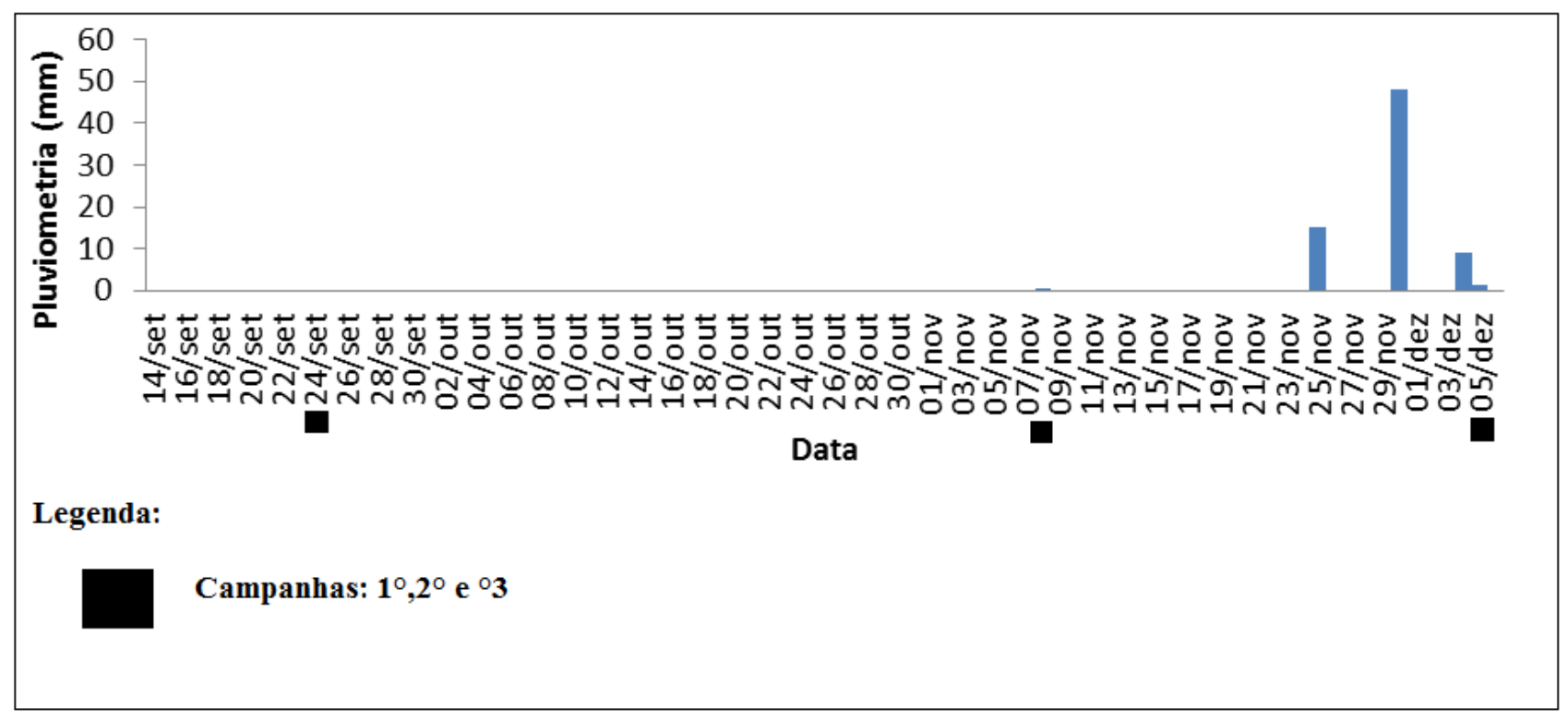

Gráfico 1 - Pluviometria

Segundo METCALF (1997) a DBO é mais difícil de se correlacionar devido aos problemas associados aos ensaios biológicos. No entanto para águas residuárias típicas, são relatadas relações entre DBO/DQO variando de 0,4 a 0,8. Em todos os pontos, desde a primeira campanha há uma correlação média de 0,4 entre DBO/DQO.

O efluente líquido gerado na base de pesquisa pode ser caracterizado como o efluente doméstico, apresentando maiores concentrações nos dias letivos (normalmente de segunda a sexta feira), principalmente no período matutino, por conta do número de alunos que frequentam o local.

As metodologias analíticas para determinação dos parâmetros físicos, químicos e microbiológicos atenderam as especificações das normas nacionais que disciplinam a matéria da edição mais recente da publicação Standard Methods of the Examination of 
Water and Wastewater, de autoria das instituições American Public Health Association (APHA), American Water Works Association (AWWA) e Water Environment Federation (WEF).

Conclusões

Podemos afirmar através dos dados coletados que o tratamento proposto, certamente apresentará êxito nos resultados obtidos (remoção). Sendo também influenciada pelas condições climáticas atuais, que favorecem o sistema proposto, no que se ressalta, a rapidez que a matéria orgânica carbonácea se degrada, como também a remoção da mesma.

Mediante a caracterização do esgoto bruto da ETE Lagoa da Cruz, propõe-se um sistema de tratamento biológico por lagoas de estabilização, sendo o sistema de lagoas: duas lagoas facultativas e uma de maturação (em série), pelo fato de ser o processo de tratamento de esgoto mais simples que se tem conhecimento e não requer demanda de energia elétrica.

Um esgoto devidamente tratado a ponto de ser devolvido aos rios é suficientemente limpo para ser reutilizado em atividades como: descargas de vasos sanitários, lavagem de carros e pisos. Com isso, sendo possível, desenvolver sistemas de reuso, desde haja comprometimento dos operários encarregados e operados de modo correto a cumprir os padrões estabelecidos pela legislação vigente, contribuindo assim para o meio ambiente e para as pessoas que dele usufrui.

\section{Referências Bibliográficas}

1. APHA. AWWA. WPCF. Standard Methods for the Examination of Water and Wastewater. 15 ed. Washington, DC.. American Public Health Association. American Water Works Association, Water Pollution control Federation,1134p. 1998. 
2. CECA. Conselho Estadual de Controle Ambiental (CECA)/MS n 003 , de 20 de junho de 1997

3. CAERN. Companhia de Águas e Esgoto do Rio Grande do Norte, 2014.

4. CEMTEC/MS, Centro de monitoramento de tempo do clima e dos Recursos Hídricos de Mato Grosso do Sul

5. CONAMA. Conselho Nacional do Meio Ambiente. Resolução n. 430 de 11 de Maio de 2011. Ministério do Meio AmbienteCONAMA. Conselho Nacional do Meio Ambiente. Resolução CONAMA N³572005, de Março de 2005.

6. EMBRAPA. Empresa Brasileira de Pesquisa Agropecuária, 2008

7. PALMEIRA, G. F. Tratamento Conjugado de Esgoto Doméstico e Lixiviado de Aterro Sanitário em Lagoas de Estabilização. TCC (Graduação) - Curso de Química Industrial, Química, Universidade Estadual da Paraíba, Campina Grande PB, 44 p., 2014.

8. VON SPERLING, M. Introdução à Qualidade das águas e ao Tratamento de Esgoto: Princípios de Tratamento Biológico de Águas Residuárias. 4a Ed. Belo Horizonte: UFMG, 2002.

9. VON SPERLING, M. Lagoas de Estabilização: Princípios do Tratamento Biológico de Águas Residuárias. 2a Ed. Belo Horizonte: UFMG, 196 p., 2002. 